\title{
Ethics and ICT Governance
}

\author{
Jacques Berleur $^{1}$, Diane Whitehouse ${ }^{2}$, Philippe Goujon ${ }^{1}$, and Catherine Flick ${ }^{1}$ \\ ${ }^{1}$ University of Namur, Namur, Belgium \\ ${ }^{2}$ The Castlegate Consultancy, Malton, United Kingdom \\ ${ }^{3}$ Institut d'Informatique, FUNDP, Namur, Belgium \\ jacques.berleur@info. fundp.ac.be, \\ info@thecastlegateconsultancy.com, philippe.goujon@fundp.ac.be, \\ catherine.flick@fundp.ac.be
}

\begin{abstract}
Human Choice and Computing is a longstanding series of conferences organised by the International Federation for Information Processing (IFIP)'s Technical Committee 9. This conference is the federation's ninth. One of its tracks concentrates on ethics and information and communication technologies (ICT) governance. A background explains why investigations of ethics and ICT governance are coming to the fore, and it shows how this has been tackled by IFIP's special interest group (SIG) 9.2.2 on a Framework for Ethics of Computing. On offer is an explanation of the purposes of the track - how to govern ICT ethically, a synthesis of its seven papers, and an overview of the results that the track is anticipated to achieve. It is hoped that, in an ever more global society, such a track and associated panel will enable a much more dynamic dialogue and exchange to take place among a wider diversity of cultures and countries, whether this is among academics, business executives, or policy-makers.
\end{abstract}

Keywords: Ethics, Governance, Information and Communication Technologies (ICT), Participative Democracy.

\section{Background}

Governance now includes a focus on participative democracy and transparency. The state is no longer the sole influence on the regulation of systems. Other actors take part at the local, regional, national, and international levels. New means of regulating scientific, technical, and other subsystems, and new ways of communicating are possible among a variety of actors.

This past decade has seen many attempts to highlight how top-down and bottom-up approaches to governance can be brought together in the ethics of computing and ICT governance. Traditional top-down forms of regulation are seen as unrepresentative by many thinkers, researchers, lobbyists, and activists. Societies' pluralism implies the growth of new forms of governance. Indeed, many international organisations are already exploring how this might take place [1]. High-level announcements on plans for a European digital agenda are anticipated by the time that Human Choice and Computing 9 takes place in September 2010. 
A multi-stakeholder approach to Internet governance, and to information and communications technologies (ICT) governance, and stakeholder engagement in the domain has become increasingly strong. However, what is meant precisely by Internet governance and a multi-stakeholder approach?

A working definition of Internet governance is the development and application by governments, the private sector and civil society, in their respective roles, of shared principles, norms, rules, decision-making procedures, and programmes that shape the evolution and use of the Internet. [2]

If the words "government" and "governance" contemporarily both seem familiar to researchers, "civil society" and the "private sector" are terms that have perhaps traditionally been less well defined, and will need more concerted efforts at determining concrete definitions. Discussions are more and more common about which kinds of organisations should be represented among the participants in civil society, and the extent to which business, business associations, and business systems are, or should be, involved in governance processes. Implicit in new forms of democracy and stakeholder involvement may be ethics that focus on fairness and justice.

Bottom-up approaches are often highly participatory in their underpinning theory, and hopefully too in their practice. Aspirations abound that the distance between rulers and the ruled, or those who govern and those who are governed, should be minimised.

In parallel with ICT governance, ethics and the ethics of computing are fields that are particularly worth deepening. A start to fundamental work along these lines already exists [3]. Descriptive approaches to the ethics of computing help to set the scene so that readers understand the context of the specific ethical dilemma and its challenges. Today, researchers and activists are seeking in a normative way to overcome these challenges. A critical approach to different sets of case studies and use-cases is under development. Participatory approaches to ICT governance are a well-known way of tackling these difficulties. They are becoming increasingly popular and widespread. At a more thoughtful ("epistemological") level, reflections on the ethics of governance are encouraged.

\section{Ethics, Governance, and the Work of the International Federation for Information Processing}

Over its fifty years of existence, the International Federation for Information Processing (IFIP) has worked to support information processing in its member countries and to encourage technology transfer to developing countries.

IFIP's special interest group (SIG) 9.2.2 focuses on a Framework on Ethics of Computing $^{1}$ is organising this particular track on ethics and ICT governance. It has been working in this domain for some twenty years, and has produced several books and monographs on the subject. As examples, we can especially cite the work of Pullinger [4], Berleur [5], Goujon et al. [3] and, more recently, Berleur et al. [6].

\footnotetext{
${ }^{1}$ http://www.info.fundp.ac.be/ jbl/IFIP/cadresIFIP.html/ (accessed on May 24, 1010).
} 
Today, IFIP SIG9.2.2 is seeking to enhance and expand the available literature in this field from a wide variety of different perspectives and locations. As a result, it anticipates to be able to develop new guidelines.

\section{Aims and Purpose of the Track}

In today's global society, politics, context, and ethics are some of the major challenges that need to be faced in the process of developing sound ICT governance arrangements.

The main aim of the Human Choice and Computing (HCC) 9's track on ethics and ICT governance is to organise a discussion that will highlight two sets of important issues: on the one hand, challenges pertinent to new forms of ICT governance; and, on the other hand, ethics. ICT governance is a crucial component of the new, and developing, field of the ethics of computing, with everything that implies in terms of research, practice, and deployment.

The authors selected for this track all focus in some way on the subject of ICT governance. The papers build from the individual to the international. In an introductory paper, governance decisions take place at the level of personal, individual choices with regard to software piracy on which the behaviour of peers could nevertheless have a substantial influence. It is also important to consider the context and background of any governance decisions and their ethics. Associations, organisations, and countries have adopted very different ways of governing processes and technologies, although many aspire to greater commonality and consensus. In this track, the countries involve Bangladesh, China, and the Maldives ${ }^{2}$. Institutions and agencies of international stature include the European Commission and the Financial Action Task Force.

In their range across such differing societal levels, the papers in this track reflect what in sociological, and even philosophical, terms are referred to as micro, meso, and macro approaches or levels. The methodologies used by each of the seven papers in this track differ considerably. Many papers - although they identify cultural, organisational, or social challenges with regard to making decisions about ICT, and managing or governing it - do not cover the relevant ethical issues in detail. It is the programme committee's aspiration that these ethical issues will emerge much more strongly in the actual track presentations, and the ensuing panel discussion on the "Ethics of computing: insights into today's key issues", which will take place in Brisbane, Australia, on Wednesday September 22, 2010.

In this track, an emphasis has been placed on the internationalism of the setting in Brisbane, Australia - in which the conference takes place, and the range of authors chosen to contribute to it. The track is characterised by the diversity of the sources of its papers. The authors focus on governance contexts that are experienced in Australia, Bangladesh, China, the Maldives, South Africa, the United Arab Emirates, the United States of America, and a variety of European countries. As a result, the track

\footnotetext{
${ }^{2}$ A much wider range of institutions and their role in governance and the ethics of computing is explored in [1]. The institutions and geographic coverage represented by the authors in this track are probably in that sense influenced by the membership organisations of IFIP, on the one hand, and by the location of the conference in the southern hemisphere, on the other.
} 
brings to light the fact that various, different aspects of ICT governance and its ethical challenges have to be scrutinised carefully when we examine the character of globalism and the richness of multiculturalism.

\section{The Individual Articles in the Track}

These papers are presented in the order in which they will appear in the track on Wednesday September 22, 2010. They progress from a level which is individual to levels which are local/regional, national, European, and international. This ordering of the papers will enable HCC9 readers and attendees to understand in more depth the notions of micro, meso, and macro levels of sociology and philosophy. The track ends with a more reflective, and theoretical, paper that examines a possible framework for the assessment of ethics and ICT governance. A discussion panel will then facilitate a wider process of dialogue and discussion.

\section{The Demographic Factors Affecting University Students' Intention to Pirate Software, Linda Spark}

Pirating software is considered to be illegal in many countries. Convention $\mathrm{n}^{\circ} 185$ on Cybercrime of the Council of Europe ${ }^{3}$ classifies it as such, at least in terms of the European Member States.

The author presents an extensive survey among South African undergraduate and graduate students on their intentions to pirate software. This study explores the demographic factors that affect the students' intentions. The students' gender and level of study appear to have the most significant effect, and their academic discipline and level of household income the least.

The author's investigation raises questions about the need for education about the ethics of software piracy, and the implications and consequences of any actions taken by them.

\section{ICT Governance versus Community Empowerment: Grassroots Evidence from Bangladesh, Mizanur Rahman}

Science, Technology and Society studies emphasise a need for multi-stakeholders, and community-led and participative approaches that strengthen the innovation process. However, contemporary surveys and benchmarking show that this ideal is not always reachable. This paper outlines three layers of community empowerment: informing, consulting and involving. ICT empowerment is said to include access, use, technological appropriation, "carrier of meaning", and social appropriation.

There are 2165 telecentres in Bangladesh for a total country population of about 120 million inhabitants, among whom $80 \%$ live in rural areas. The aim is to ensure that, by 2020, each Union Parishad (an administrative entity of about 25,000 inhabitants) should have at its disposal a Union Information Centre that enables the local citizens to access information.

The paper's conclusion with regard to ICT empowerment is realistic. It shows that, regardless of whether the local government authorities are using older or newer forms

3 The Council of Europe. Action against Economic Crime (accessed on May 24, 2010), http://www.coe.int/t/DGHL/cooperation/economiccrime/cybercrime/default_en.asp/ 
of ICT, people's empowerment is far from being a reality. No ethical conclusion is derived in this paper, but a political challenge is surely open.

\section{Exploring the Digital Divide in the Maldives, Mohamed Shareef, Adegboyega Ojo, and Tomasz Janowski}

The Maldive Islands in the Indian Ocean constitute an archipelago of 26 natural coral atolls. There are around 1,192 small low-lying islands, of which 194 are permanently inhabited. Only four of these islands have a population of over 5,000. One hundred and thirty-one of them have a population which is below 1,000; seventy-two have a population below 500. The distance north-south is 823 kilometres, and west-east is 130 kilometres. The range is quite obvious.

The paper starts by defining rapidly, and with acuity and interest, the concept of the digital divide. It takes into account the different factors which enable people to benefit from digital technology, and those which do not. The paper answers two main questions: How are the atolls of the Maldives divided with respect to access to ICT, and how significant is the geographical distribution and demography of the atolls to the digital divide? Its results are convincing. The analysis shows clearly that there is no digital divide with respect to mobile phones. There is, however, a large difference in terms of the penetration of the household use of both Internet and personal computers. The difference between the capital city, Male', and the remainder of the Maldives' atolls is significant.

While the challenges of geographic dispersal and population density to ICT development are fairly well accepted, the analysis of the paper shows that the relationship between these characteristics and the creation of the digital divide are more complex.

The ethical issues which probably underlie the paper are not made explicit, however. An analysis of literacy as in the International Telecommunications Union's Digital Access Index could have helped to open up that discussion ${ }^{4}$.

\section{Balancing Public and Private Interests in ICT Standardisation: The Case of AVS in China, Junbin Su and Vladislav Fomin}

This paper proposes a way to reconcile the vested interests of patent holders, intellectual property rights, and the public through a "Fair, rational and non-discrimination" (FRAND) and royalty-free standard-setting process. It focuses on the case of the Audio Video Coding Standard (AVS) established by the Ministry of Information Industry of China in 2002. The AVS example can be applied in other ICT standardisation processes. A more comprehensive model of committee standardisation called the "Public Dominated Model" has been derived from it.

The process to define the AVS has led to the development of a theoretical model that deals with the conflict of interests. The standard is protected from a kind of monopoly of rents by a few companies where the public interest is often neglected and where the holders of essential patents obey the FRAND. This presupposes a balanced representation of the stakeholders. AVS is inspired by the development of MPEGfamily standards. What is different is the policy on intellectual property rights.

\footnotetext{
${ }^{4}$ International Telecommunications Union, Digital Access Index (accessed on May 24, 2010), http://www.itu.int/ITU-D/ict/dai/
} 
The FRAND proposal belongs surely to the field of Science, Technology and Society studies. However, it is not yet entirely clear why the AVS model privileges public research institutes and universities among its various stakeholders. The authors explore the complexity of public-private dilemmas in ICT standardisation-setting.

\section{The European VCD Service: Facilitating Public Procurement through Criteria to Evidence Mapping, Ansgar Mondorf and Maria A. Wimmer}

This paper develops a model which favours interoperability among European interstate commissioning ("procurement"). One of the key building blocks which has emerged from the European Commission co-funded project on Pan-European Public Procurement On-Line (PEPPOL) is the Virtual Company Dossier (VCD). The idea of this model is to facilitate the appropriate mapping of national criteria in a common tendering process, and to support the mutual recognition - among Member States - of certificates and qualification documents which satisfy the appropriate legal, organisational, semantic and technical interoperability criteria in Europe. The paper makes explicit a set of specific rules to do this.

As an eCommerce or eGovernment paper, this paper falls in the governance domain. However, its purely technical approach does not immediately enable the identification of any underlying ethical principles.

\section{Money Laundering and FATF Compliance by the International Community, Ali Alkaabi, George Mohay, Adrian McCullagh, and Nicholas Chantler}

The International Financial Action Task Force (FATF) has established 40 recommendations against money laundering, and nine special recommendations for combating the financing of terrorism. In this paper, the authors examine how four countries have implemented those recommendations in their legal systems, preventive measures, and institutional and other measures. The four countries are: Australia, the United Arab Emirates (UAE), the United Kingdom (UK), and the United States of America (USA). The analysis of FATF compliance shows that the USA (with 34 implemented recommendations), followed by the UK (29) and Australia (21), are fully or largely compliant with the anti-money laundering recommendations; the UAE is the least compliant country (17). With regard to the nine specific recommendations, the order of compliance remains the same (in descending order, 9, 8, 5 and 3). In both cases, the UAE is the least compliant vis-à-vis the recommendations.

From a HCC9 viewpoint, it is interesting to try to understand the reasons why the situation is like this. A first explanation is that the founding members of the FATF like Australia, the UK and the USA - which did not include the UAE - have left their unavoidable, cultural imprints on the organisation and its operations. But there are other factors that appear to affect the degree of compliance. The authors offer examples such as culture, faith, and socio-economic elements. They note that:

... the culture and legal systems support each other and that economic development and financial structures are affected not only by a country's legal system but also by its culture and show that development of a country's legal and financial system is related to its religious beliefs.

and,

Islam prohibits any activity funded by money derived from unlawful trade or illgotten property and prohibits using illegal money for charities. Money gained 
from gambling and bank interest is prohibited in Islam. This is in marked contrast to normal practice in Australia, the UK and the USA.

There are also social, economic and financial factors:

The UAE is a cash-based economy: in it, carrying large cash amounts is a normal practice and this makes it more difficult to impose requirements concerning reporting large cash transactions. Imposing regulations (for instance, requiring all large transactions to be reported) in such circumstances is very difficult if not impossible.

The authors conclude that these various factors present a challenge to the international community and to the FATF. These dilemmas can only be resolved by careful, country by country, consideration of local factors.

\section{Ethical Governance for Emerging ICT: Opening Cognitive Framing and Achieving Reflexivity, Philippe Goujon and Catherine Flick}

This paper's aim is to find new ways to address the ethical problems raised by ICT. The paper draws on examples of technological development projects supported by the European Commission's latest research and technological development Framework Programme (2007-2013).

Many such projects are subject to a strong push for technology development. It too often obscures the need for any deep form of ethical consideration prior to a technical project being funded, developed or deployed. Ethics can become an "add-on", a sort of accessory or instrumentalised guarantee.

In this context, expertise, whether it is philosophical or scientific, becomes the indisputable new source of normativity. The problems revealed are confined to a scientific perspective alone; this means that the challenges taken into account are confined to the realm of strict scientific rationality. Democracy is confiscated.

The authors illustrate the limitations of technology assessment. They show that the cognitive framing of the assessment process is often biased by expertise. Thus, such assessments might simply represent, or remain, a means of designing the social acceptance or acceptability of a specific technology.

There is a variety of elements ("conditions") which need to be borne in mind. What is called in this paper, the "opening of the cognitive framing" is a preliminary condition for a real social and ethical approach. However, there are other conditions: norms and ways of life have to be addressed; dominant norms need to be challenged by minority norms; and a "second-order reflexivity" should encourage a testing of the governance process for its social legitimacy.

The authors introduce the theory and approach of Belgian theorists, Jacques Lenoble and Marc Maesschalck [7]. These philosophers advocate a form of "progressive reflexive governance". This kind of governance process enables the actors who are involved in any technological project or initiative to organise themselves in a way that would enable them to think about their own construction of the particular project's framing, context, and norms. The terms - such as framing, context, and norms - are explained in the paper. The track programme committee is interested to explore the appropriateness and application of these ideas in an international setting. 


\section{An Overview of the Track}

These papers on ICT governance and the ethics of computing build from the individual to the international. They first investigate elements of self-governance at the individual level: for example, in terms of activity around software piracy and the degree of control that individuals may have on their own actions and peer groups on them. They progressively examine how associations, organisations, and countries can govern their choices with regard to computing and the Internet. Last but not least, a framework is provided for a way to look at ethics of computing cases, contexts, and ways of organising. To date, it has been tested largely only in the Benelux countries or in wider European settings. It is a considerable challenge to assess its application to a wider international context.

The panel will come at the end of the papers represented by this track. It is likely to concentrate even more on the ethical issues that surround computing than on the governance arrangements. It will deliberately expose in a more structured manner what are called the micro-meso-macro (bottom, middle, and high) levels of the ethics of computing. It will draw on a mix of voices and opinions which come from a diversity of geographic and cultural settings. In an ever more global society, it is hoped that such a track can help to explore more dynamic forms of dialogue and sharing among a wider diversity of cultures, communities, and countries.

The programme committee urges not only an enjoyment of the reading of these papers on ICT governance and the ethics of computing, but also quiet reflection on their meaning and more systematic application of that meaning in action.

Acknowledgments. As track programme chairs, we thank all the programme committee members for their efforts in supporting the organisation of this track. In this respect, we would especially like to acknowledge the following for their intellectual and organisational inputs: Julie Cameron, Penny Duquenoy, Richard Delmas, Françoise Massit, Marc Griffiths, Marc van Lieshout, Gunnar Wenngren, and Chris Zielinski. We are cognisant of the efforts of John Weckert in agreeing to cochair the track's panel discussion on the "Ethics of computing: insights into today's key issues".

\section{References}

1. Berleur, J.: Governance Challenges: First Lessons from the WSIS - An Ethical and Social Perspective. In: Goujon, P., Lavelle, S., Duquenoy, P., Kimppa, K., Laurent, V. (eds.) IFIP International Federation for Information Processing. The Information Society: Innovation, Legitimacy, Ethics and Democracy, vol. 233, pp. 225-259. Springer, Boston (2007)

2. World Summit on the Information Society (WSIS), The Tunis Agenda. See especially articles $\S \S 29-82$, and $\S 34$,

http://www.itu.int/wsis/documents/ doc_multi.asp? lang=en\&id=22670 (accessed on May 24, 2010)

3. Goujon, P., Lavelle, S., Duquenoy, P., Kimppa, K., Laurent, V.: The Information Society: Innovation, Legitimacy, Ethics and Democracy. Springer, Boston (2007) 
4. Pullinger, D.: Society, Religions and Information Technology. In: Berleur, J., Clement, A., Sizer, R., Whitehouse, D. (eds.) The Information Society: Evolving Landscapes, pp. 124144. Springer-Verlag and Captus University Publications, New York (1990)

5. Berleur, J.: Culture and democracy revisited in the global information society: Summary of a position paper. In: Berleur, J., Whitehouse, D. (eds.) An Ethical Global Information Society: Culture and Democracy Revisited, pp. 3-11. Chapman \& Hall, London (1997)

6. Berleur, J., Duquenoy, P., Gotterbarn, D., Goujon, P., Kimppa, K., Six, B., Weber-Wulff, D. (eds.): Ethics of Computing Committees: Suggestions for Functions, Form and Structure. On behalf of IFIP SIG9.2.2. IFIP, Laxenburg, Austria (2008)

7. Lenoble, J., Maesschalck, M.: Towards a Theory of Governance: The Action of Norms. Kluwer Law International, The Hague (2003) 